\title{
Investigation of the Sorption Properties of Ore Materials for the Removal of Sulfur Dioxide From Exhaust Flue Gases of Power Plants
}

\author{
Ismagilov Z.R. ${ }^{1,2,3}$, Shikina N.V. ${ }^{2}$, Khairulin S.R. ${ }^{2}$, Kuznetsov V.V. ${ }^{2}$, Rudina N.A. ${ }^{2}$, \\ Teryaeva T.N. ${ }^{1}$, Mikhailova E.S. ${ }^{3}$, \\ ${ }^{1}$ T. F. Gorbachev Kuzbass State Technical University \\ Kemerovo, Russian Federation \\ ${ }^{2}$ Boreskov Institute of Catalysis \\ Novosibirsk, Russian Federation \\ ${ }^{3}$ Institute of Coal Chemistry and Materials Science \\ Kemerovo, Russian Federation
}

\begin{abstract}
The prospects of using a natural material ferromanganese nodules (FMN) from the Gulf of Finland as the $\mathrm{SO}_{2}$ adsorbent are discussed. The starting material was studied as pellets and powder using $X$-ray fluorescence spectroscopy, XRD, BET, and mechanical strength analysis; dependences of physicochemical parameters of the material on heat treatment at 100$1000^{\circ} \mathrm{C}$ were found. FMN samples were tested in the process of $\mathrm{SO}_{2}$ sorption. The sorptive capacity of FMN samples for $\mathrm{SO}_{2}$ was found to increase with humidity of adsorbents; FMN samples with a humidity above $40 \%$ were shown to be promising for the removal of sulfur dioxide from gases.
\end{abstract}

Keywords - SO2 removal, adsorbent, sorptive capacity, ferromanganese nodules, natural adsorbents

\section{INTRODUCTION}

Generation of electrical and heat energy is accompanied by a large-scale interchange of matter and energy with the environment, thus producing a detrimental effect that should be remediated.

Catalytic combustion is the way to radically improve the efficiency of power production and minimize its detrimental effect on the environment [1-4]; however, electrical and heat energy is now produced mostly at conventional power plants, with coal playing the dominant role in the fuel balance.

Modern power plants with an output of 2.4 million $\mathrm{kW}$ consume up to 20 thousand tons of coal per day and emit to the atmosphere up to 680 tons of $\mathrm{SO}_{2}$ and $\mathrm{SO}_{3}$ (at a $1.7 \%$ sulfur content in the inlet fuel).

The content of sulfur dioxide can be decreased by chemisorption purification, which is able to completely remove sulfur dioxide from the exhaust flue gases.

The materials containing oxides of alkali-earth elements, $\mathrm{CaO}$ and $\mathrm{MgO}$, are conventionally used as sorbents [5-7]; however, such materials are quite expensive, which stimulates a search for alternative sorption systems.
Of particular interest for the removal of sulfur dioxide from flue gases is the use of inexpensive and harmless natural sorbents containing metal oxide and hydroxide compounds. In a series of works [8-11], T.J. Bandosz and co-authors studied the adsorption of sulfur dioxide on inexpensive sorbents obtained by the pyrolysis of sewer sludge at $400-900^{\circ} \mathrm{C}$. These sorbents contain $20-40 \%$ carbon, up to $3-5 \% \mathrm{Fe}$ and $4-5 \% \mathrm{Ca}$ as oxides as well as oxides of other metals: $\mathrm{Mg}, \mathrm{Cu}, \mathrm{Zn}, \mathrm{Cr}$, Al. High specific surface area (up to $880 \mathrm{~m}^{2} / \mathrm{g}$ ) and pore volume (up to $0.46 \mathrm{~cm}^{3} / \mathrm{g}$ ) along with the presence of metal oxides in the sorbent composition provide quite a high dynamic capacity for sulfur dioxide (up to $50 \mathrm{mg} / \mathrm{g}$ ). Investigation of sulfur dioxide adsorption $(0.3 \%$ in air) at room temperature revealed that humidification of the gas stream (up to a relative humidity of $80 \%$ ) results in a more efficient adsorption of $\mathrm{SO}_{2}$ : under such conditions, dynamic capacity of the sorbent was approximately two times higher as compared to the dry gas [12]. The beneficial effect of water on $\mathrm{SO}_{2}$ adsorption is attributed to the formation of surface hydroxyl groups in metal oxides. Manganese dioxide in the composition of manganese ores and specially prepared adsorbents serves as an efficient adsorber of sulfur dioxide and hydrogen sulfide [13-17]. A comprehensive review of the catalytic and sorption properties of ferromanganese ores was made by M. Nitta [18], who demonstrated that ferromanganese ore is a promising material for purification of gases from toxic impurities, in particular sulfur dioxide, hydrogen sulfide, ammonia, and heavy metal ions $(\mathrm{Hg}, \mathrm{Pb}, \mathrm{Cd}$ and others).

For the first time a method for the application of manganese ore as a sorbent of sulfur dioxide was reported in 1967 as a US patent [19]. It was shown that the ore is an efficient adsorber of $\mathrm{SO}_{2}$ as a component of waste gases from boilers and furnaces at a concentration of $0.04-1.2 \%$ and WHSV of $1000 \mathrm{~h}^{-1}$ and can be used for purification of ambient air from $\mathrm{SO}_{2}$ at the initial concentration of $25 \mathrm{ppm}$ or $\mathrm{H}_{2} \mathrm{~S}(10$ $\mathrm{ppm})$ at WHSV of ca. $10000 \mathrm{~h}^{-1}$. The removal of $\mathrm{SO}_{2}$ from gases is accompanied by accumulation of sulfates in the sorbent, which decreases its adsorption activity. When more 
than 15 wt.\% $\mathrm{SO}_{2}$ with respect to the starting ore weight is adsorbed, the adsorbent is regenerated to remove the accumulated sulfates by washing with water; after that the sorbent can be reused. Therewith, efficiency of the sorbent remains high for a long time. As shown in [20], the adsorption of sulfur dioxide by a water pulp containing 3-20\% of the ore provides a 95-99\% purification and virtually a complete sulfation of nickel, cobalt and manganese.

Thus, the information available from scientific and patent literature makes it possible to estimate the prospects of using ferromanganese ore as a $\mathrm{SO}_{2}$ sorbent. In this connection, of particular interest are the shelf ferromanganese nodules (FMN), whose rich deposits have been found in the water areas of Russian seas. $50 \%$ of the ore component of such nodules is represented by complex composites of $\mathrm{Mn}$ and $\mathrm{Fe}$ hydroxides and oxides. Up to $90 \%$ of the ore substance is in the X-ray amorphous state. Manganese minerals in the nodules include birnessite, buserite, cryptomelane and the X-ray amorphous mass of a wad-psimelane composition. The ferric component of the nodules is represented by ferrihydrite, hydrogoethite and lepidocrocite [21].

Our work was aimed to study physicochemical characteristics of ferromanganese nodules from the bottom of the Gulf of Finland and to assess the possibility of their use as adsorbents of sulfur dioxide.

\section{EXPERIMENTAL}

\section{A. Materials}

Sorbent of SO2 were prepared using the pelletized and powdered material "Ore of ferromanganese nodules from the Gulf of Finland” Specs 0731-001-50855050-2005”.

\section{B. Methods}

\section{1) Determination of the chemical composition}

The elemental composition of the samples was determined by X-ray fluorescence spectroscopy on a VRA-30 analyzer with the $\mathrm{Cr}$ anode of X-ray tube. Prior to measurements, pellets of the test sample with the addition of boric acid or cellulose were prepared. A result of the analysis was obtained as the arithmetic mean of two parallel measurements diverging from one another by no more than $2 \%$. The allowed relative total measurement error was $\pm 0.05 \%$ at a confidence level of 0.95 .

\section{2) Determination of the phase composition}

Phase composition of the samples was determined by analyzing the diffraction patterns obtained on an HZG-4 diffractometer using monochromatic $\mathrm{Cu} \mathrm{K} \mathrm{K}_{\alpha}$ source. The observed phases were identified with the use of JCPDS radiographic database.

\section{3) Specific surface area and pore volume measurements}

Pore structure of the samples was examined by the lowtemperature nitrogen adsorption on an ASAP-2400 (Micromeritics, USA) instrument at the liquid nitrogen temperature, $77 \mathrm{~K}$, after pretreatment of the samples at $150^{\circ} \mathrm{C}$ and a residual pressure below $0.001 \mathrm{~mm} \mathrm{Hg}$; the samples were subjected to a standard pretreatment by the BET and BarrettJoyner-Halenda (BJH) methods.

\section{4) Bulk density measurements}

Bulk density was measured according to GOST 16190. A dried sample was placed in a $100 \mathrm{~cm}^{3}$ volumetric flask and packed by shaking down. After that, weight of the sample in this volume was determined. Bulk density $(\rho)$ expressed in $\mathrm{g} / \mathrm{cm}^{3}$ was calculated by the formula: $\rho=\mathrm{m} / \mathrm{V}$, where $\mathrm{m}$ is the sample weight, $\mathrm{g}$; and $\mathrm{V}$ is the sample volume, $\mathrm{cm}^{3}$. A result of the measurement was obtained as the arithmetic mean of two parallel measurements diverging from one another by no more than $0.01 \mathrm{~g} / \mathrm{cm}^{3}$. The allowed total measurement error was $\pm 0.005 \mathrm{~g} / \mathrm{cm}^{3}$ at a confidence level of 0.95 .

\section{5) Mechanical strength measurements}

Mechanical strength was measured using an MP-9C instrument intended for measuring the strength of porous dispersed solids under static conditions. The essence of the method consists in measuring the breaking force applied to the generating line of each pellet of the catalyst sample between two parallel planes. For testing, no less than 30 pellets were selected from each sample. The pellets should not have visible damages and shape defects. The length and diameter of the pellets were measured once using a caliper; after that, the pellets were dried at a temperature of $110 \pm 10^{\circ} \mathrm{C}$ at least for 2 h. The dried sample was transferred into an exiccator and cooled to room temperature. For measurements, a metal template represented by a plate with a cylindrical pit in the middle was placed on a stage. The prepared pellet was mounted in the pit; the lower stage was moved to the upper plane of the instrument using a hoisting gear. The pellet was uniformly loaded until its failure occurred. The moment of the pellet failure was fixed visually from the reverse motion of the pointer. A load that destructs the sample was indicated by the detector at the moment of failure. Mechanical strength of the pellets $\left(\mathrm{P}_{\mathrm{i}}\right)$ expressed in $\mathrm{MPa}$ (or in $\mathrm{kg} / \mathrm{cm}^{2} * 10$ ) was calculated as a ratio of the breaking force to the sectional area using the formula

$$
\mathrm{Pi}=\mathrm{N} \cdot \mathrm{A} / \mathrm{S} \cdot 10,
$$

where $\mathrm{N}$ is the indicated value, scale division;

$\mathrm{A}$ is the calibration factor equal to 0.6025 ;

$\mathrm{S}$ is the sectional area of the test pellet, $\mathrm{cm}^{2}$, which is calculated as

$$
\mathrm{S}=\mathrm{L} \cdot \mathrm{D},
$$

where $\mathrm{L}$ is the length of a cylindrical pellet, $\mathrm{cm}$; and

$\mathrm{D}$ is the pellet diameter, $\mathrm{cm}$.

A result was represented by the arithmetic mean of 30 parallel measurements.

\section{6) Moisture capacity measurements}

Moisture capacity characterizes the pore volume of a sample accessible to water. To measure moisture capacity with respect to water, the weighed sample $\left(\mathrm{m}_{\mathrm{o}}\right)$ was placed in a capped glass weighing bottle and poured with distilled water so that the water level was $1 \mathrm{~cm}$ above the pellets. After 30 
min, water was decanted from the pellets. The pellets were placed on a plastic sieve and subjected to air blasting to remove excess moisture. The sample impregnated with water was weighed $\left(\mathrm{m}_{1}\right)$; after that, moisture capacity was calculated by the formula

$$
\text { Moisture capacity }=\left(\mathrm{m}_{1}-\mathrm{m}_{\mathrm{o}}\right) / \mathrm{m}_{\mathrm{o}}
$$

\section{7) Sorptive capacity measurements}

The experiments on $\mathrm{SO}_{2}$ sorption were carried out in a laboratory setup. Its schematic is displayed in Fig. 1.

A $\mathrm{SO}_{2}$-containing mixture $\left(1 \% \mathrm{SO}_{2}\right.$ in air) from vessel (1) was delivered to the reactor through stopcock (2) and gas batching unit BDG-85 (3). The adsorbent sample (1.1 g for dry samples with a humidity of $14-18 \% ; 1.5 \mathrm{~g}$ for wet samples with a humidity of 43-50\%), a $0.5-1.0 \mathrm{~mm}$ fraction, was placed in glass reactor (4) with the inner diameter of $6 \mathrm{~mm}$. The $\mathrm{SO}_{2}$-containing mixture was fed at a rate of $60 \mathrm{ml} / \mathrm{min}$. $\mathrm{SO}_{2}$ sorption was performed at room temperature, and then at $50,90,150$ and $350^{\circ} \mathrm{C}$.

The concentration of $\mathrm{SO}_{2}$ in the gas mixture after the reactor was determined by a Kristall-2000M gas chromatograph equipped with a FID detector. Argon was used as a carrier gas. The gas mixture was separated on a chromatographic column HayeSep $\mathrm{C}+0.5 \% \mathrm{H}_{3} \mathrm{PO}_{4}, \varnothing 3 \mathrm{~mm}$, $\mathrm{L}=3 \mathrm{~m}$ at a column temperature of $100^{\circ} \mathrm{C}$. The method of analysis was described elsewhere [22].

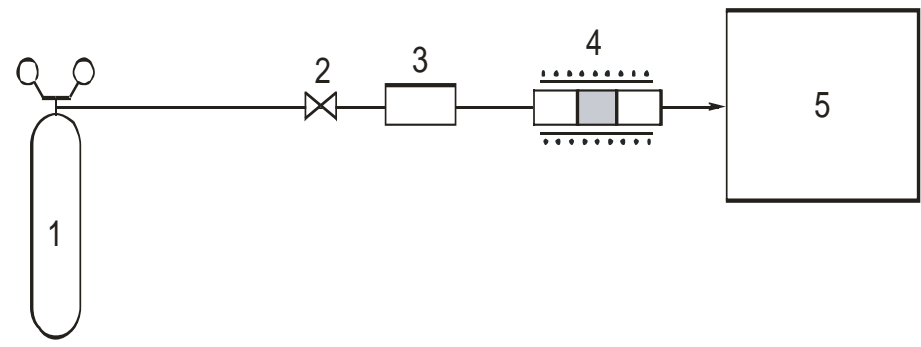

Fig. 1. Schematic of the setup for investigation of $\mathrm{SO}_{2}$ sorption: 1 - a vessel with $\mathrm{SO}_{2}$-containing mixture $\left(1 \% \mathrm{SO}_{2}\right.$ in air); 2 - stopcock; 3 - gas batching unit BDG-85; 4 - reactor; 5 - a Kristall-2000M gas chromatograph.

8) Calculation of the sorptive capacity for $\mathrm{SO}_{2}$

Sorptive capacity for $\mathrm{SO}_{2}$ before a breakthrough of sulfur dioxide from the reactor was expressed in grams of adsorbed $\mathrm{SO}_{2}$ per gram of the moisture-free adsorbent and calculated as

$$
\xi=\frac{V \cdot C_{S O 2} \cdot M_{S O 2}}{22400} \cdot \frac{\tau_{o}}{m_{c}}, \text { where }
$$

$\xi$ - sorptive capacity, $\mathrm{g}_{\mathrm{SO}_{2}} / \mathrm{g}_{\mathrm{dry}}$ adsorbent

$V$ - feed rate of $\mathrm{SO}_{2}$-containing mixture to the reactor, $\mathrm{cm}^{3} / \min$

$C_{\mathrm{SO}_{2}}$ - concentration of $\mathrm{SO}_{2}$ in the mixture, volume fractions $M_{\mathrm{SO} 2}=64 \mathrm{~g} / \mathrm{mol}-\mathrm{SO}_{2}$ molar mass

$\tau_{o}$ - time before the start of $\mathrm{SO}_{2}$ outlet from the reactor, min $m_{c}$ - weight of the moisture-free adsorbent, $\mathrm{g}$

\section{RESULTS AND DISCUSSION}

\section{A. Investigation of physicochemical parameters of the starting material}

The average sample was taken from a batch of FMN ore with the pellet size of 7-12 $\mathrm{mm}$. This sample was used to measure the total humidity ( hum), specific surface area $\left(\mathrm{S}_{\mathrm{sp}}\right)$, moisture capacity $\left(\mathrm{V}_{\Sigma}\right.$ with respect to $\left.\mathrm{H}_{2} \mathrm{O}\right)$, and mechanical crushing strength $(\mathrm{P})$. These parameters were studied in dependence on the calcination temperature. Chemical analysis for the main elements was made with a sample calcined at $550^{\circ} \mathrm{C}$. The results are listed in Table 1 .

The average sample from a batch of powdered FMN was used to find the total humidity ( hum) and specific surface area $\left(\mathrm{S}_{\mathrm{sp}}\right)$; chemical analysis for the main elements was performed with a sample calcined at $550^{\circ} \mathrm{C}$ (Table 2).

The FMN samples calcined at $100-400^{\circ} \mathrm{C}$ have quite high values of specific surface area, $150-158 \mathrm{~m}^{2} / \mathrm{g}$, which is determined by the number of fine pores. Investigation of the pore structure of FMN samples by nitrogen adsorption and determination of the pore volume with respect to water showed that an increase in the calcination temperature from 100 to $400^{\circ} \mathrm{C}$ decreases the number of fine pores with the size of $40 \AA$ and increases the total pore volume from 0.65 to 0.89 $\mathrm{cm}^{3} / \mathrm{g}$. This is caused not only by transformation of the skeleton of FMN samples due to sintering of the fine pores but mostly by burnout of organic inclusions and formation of cavities in the pellets. As the calcination temperature is raised above $550^{\circ} \mathrm{C}$, the mesopore volume sharply decreases and large pores gradually sinter, which is accompanied by deterioration of all parameters of the pore structure, both the specific surface area and the total pore volume.

The phase composition of a dry sample of FMN ore includes the X-ray amorphous phase and phases that cannot be identified using the radiographic database. To identify such phases, the FMN sample was heat treated at $200-1000^{\circ} \mathrm{C}$. We expected that this treatment would lead to crystallization of compounds constituting the ore, which could show up in the diffraction pattern. This experiment revealed the crystallized phases of hematite, magnetite and quartz in the samples calcined at $700^{\circ} \mathrm{C}$, although trace amounts of the magnetite phase were present also in the low-temperature samples $\left(\mathrm{T}_{\text {calc }}\right.$ of 300 and $500^{\circ} \mathrm{C}$ ). The phase composition of sample $1000^{\circ} \mathrm{C}$ is similar to that of sample $700^{\circ} \mathrm{C}$, except for the appearance of an additional phase, which was not identified using the radiographic database. The crystallized phases of manganese compounds are not observed in the diffraction patterns of the samples calcined at $1000^{\circ} \mathrm{C}$.

The study has demonstrated that the ore of ferromanganese nodules has a developed pore system and a high content of Mn and $\mathrm{Fe}$ compounds in the amorphous state; this forms a basis for possible applications of such materials as the promising sorbents of acid gases. 
TABLE 1. Physicochemical Properties of FMN Pellets

\begin{tabular}{|c|c|c|c|c|c|c|}
\hline No. & $\begin{array}{c}\text { Drying and } \\
\text { calcination } \\
\text { temperature, }{ }^{\circ} \mathrm{C}\end{array}$ & shum, \% & $\mathrm{S}_{\mathrm{sp}}, \mathrm{m}^{2} / \mathrm{g}$ & $\begin{array}{c}V_{\Sigma} \text { with } \\
\text { respect to } \\
\mathrm{H}_{2} \mathrm{O}, \mathrm{cm}^{3} / \mathrm{g}\end{array}$ & $P, \mathrm{~kg} / \mathrm{cm}^{2}$ & $\begin{array}{c}\text { Chemical } \\
\text { composition } \\
\left(\mathbf{5 5 0}^{\circ} \mathrm{C}\right), \text { wt. } \%\end{array}$ \\
\hline 1 & $\begin{array}{l}\text { Starting dry } \\
\text { sample }\end{array}$ & 50.3 & not determ. & not determ. & not determ. & \multirow{7}{*}{$\begin{array}{c}\mathrm{Fe}=25.21 \\
\mathrm{Mn}=23.29 \\
\mathrm{Al}=5.26 \\
\mathrm{Si}=9.86 \\
\mathrm{P}=4.84 \\
\mathrm{~S}=1.13 \\
\mathrm{~K}=3.33 \\
\mathrm{Mg}<2 \\
\mathrm{Na}<3 \\
\mathrm{Ca}=1-2\end{array}$} \\
\hline 2 & $25 / 24 \mathrm{~h}$ & 19.3 & 120 & not determ. & not determ. & \\
\hline 3 & $100 / 3 \mathrm{~h}$ & 15.9 & 150 & 0.65 & 6.0 & \\
\hline 4 & $200 / 3 \mathrm{~h}$ & 9.5 & 154 & 0.76 & 6.0 & \\
\hline 5 & $300 / 3 \mathrm{~h}$ & 1.9 & 148 & 0.79 & 5.5 & \\
\hline 6 & $400 / 3 \mathrm{~h}$ & 1.5 & 152 & 0.89 & 5.2 & \\
\hline 7 & $550 / 3 \mathrm{~h}$ & 0 & 78 & 0.66 & 5.5 & \\
\hline
\end{tabular}

TABLE 2. Physicochemical Properties of FMN Powder

\begin{tabular}{|c|c|c|c|c|c|}
\hline No. & $\begin{array}{l}\text { Drying and } \\
\text { calcination } \\
\text { temperature, }{ }^{\circ} \mathrm{C}\end{array}$ & shum, \% & $S_{s p}, m^{2} / g$ & Phase composition & $\begin{array}{l}\text { Chemical composition } \\
\left(550^{\circ} \mathrm{C}\right), \text { wt. } \%\end{array}$ \\
\hline 1 & Starting sample & 20.5 & not determ. & $\begin{array}{l}\text { - X-ray amorphous phase } \\
\text { - phases not identified from } \\
\text { radiographic database }\end{array}$ & \multirow{10}{*}{\begin{tabular}{ccc}
\multicolumn{2}{c}{$\mathrm{Fe}=25.13$} & \\
$\mathrm{Mn}=23.39$ & $\mathrm{Al}=$ \\
& 4.91 & \\
& $\mathrm{Si}=10.75$ & \\
$\mathrm{P}=4.98$ & & $\mathrm{~S}=$ \\
& 1.01 & $\mathrm{Mg}<2$ \\
$\mathrm{~K}=3.31$ & & \\
& $\mathrm{Na}<3$ & \\
$\mathrm{Ca}=1-2$ &
\end{tabular}} \\
\hline 2 & $25 / 24 \mathrm{~h}$ & 17.8 & 113 & not determ. & \\
\hline 3 & $100 / 3 \mathrm{~h}$ & 14.3 & 153 & not determ. & \\
\hline 4 & $200 / 3 \mathrm{~h}$ & 9.0 & 155 & & \\
\hline 5 & $300 / 3 \mathrm{~h}$ & 1.6 & 158 & $\begin{array}{c}\alpha-\mathrm{SiO}_{2} \\
\text { - magnetite traces } \\
\text { - unidentified phase }\end{array}$ & \\
\hline 6 & $400 / 3 \mathrm{~h}$ & 1.0 & 150 & & \\
\hline & & & & $\begin{array}{c}-\alpha-\mathrm{SiO}_{2} \\
\text { - magnetite traces }\end{array}$ & \\
\hline 7 & $550 / 3 \mathrm{~h}$ & 0 & 65 & $\begin{array}{c}\text { - X-ray amorphous phase } \\
\text { - phase not identified from } \\
\text { radiographic database, close to } \\
\mathrm{KFeSi}_{3} \mathrm{O}_{8}\end{array}$ & \\
\hline 8 & $700 / 3 \mathrm{~h}$ & not determ. & 12 & $\begin{array}{c}\text { - hematite } \mathrm{Fe}_{2} \mathrm{O}_{3} \\
\text { - magnetite } \mathrm{Fe}_{3} \mathrm{O}_{4} \\
\text { - } \alpha-\mathrm{SiO}_{2} \\
\text { - unidentified phase }\end{array}$ & \\
\hline 9 & $1000 / 3 \mathrm{~h}$ & not determ. & 1.0 & $\begin{array}{c}\text { - hematite } \mathrm{Fe}_{2} \mathrm{O}_{3} \\
\text { - magnetite } \mathrm{Fe}_{3} \mathrm{O}_{4} \\
-\alpha-\mathrm{SiO}_{2} \\
\text { - two unidentified phases }\end{array}$ & \\
\hline
\end{tabular}

\section{B. A study of the sorption properties of FMN}

In the experiments, the sorptive capacity of $\mathrm{FMN}$ for $\mathrm{SO}_{2}$ was examined in dependence on humidity of the starting FMN at the adsorption temperature of $25^{\circ} \mathrm{C}$ and on the temperature of adsorption process on dry and wet samples.

The dependence of sorption properties of FMN samples on their humidity was studied with the following FMN samples: the starting sample with a humidity of $43 \%$; the sample that was dried at $100^{\circ} \mathrm{C}$ and supplemented with water to a humidity of $43 \%$; the sample that was dried in air to a humidity of $18 \%$; and the sample that was dried at $100^{\circ} \mathrm{C}$ to a humidity of $14 \%$. Results of the study are listed in Table 3.

The dependence of sorption properties of the samples on the sorption temperature was examined using the FMN samples: the dry sample with a humidity of $43 \%$; the sample dried at $100^{\circ} \mathrm{C}$ to a humidity of $14 \%$; and the sample dried at 
$100^{\circ} \mathrm{C}$ and supplemented with water to a humidity of $43 \%$. The results obtained are shown in Table 4 and Fig. 2.

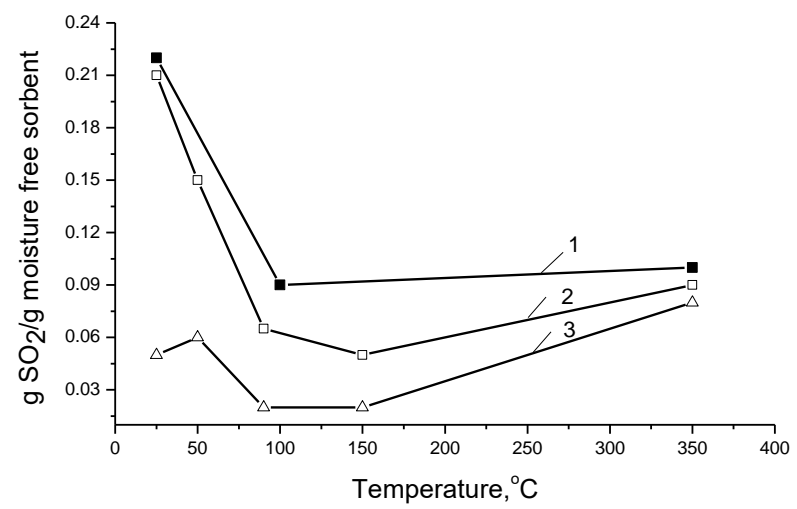

Figure 2. Sorptive capacity of FMN versus humidity of material and sorption temperature: $1-$ FMN wet (Humidity $=$

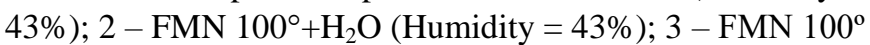
$($ Humidity $=14 \%)$

TABLE 3. Sorptive Capacity of FMN Samples for $\mathrm{SO}_{2}$ Versus FMN humidity

\begin{tabular}{|c|c|c|c|c|c|}
\hline No. & Sample & $\begin{array}{c}\text { Sample } \\
\text { weight, } \\
\text { g }\end{array}$ & $\begin{array}{c}\text { Adsorption } \\
\text { temperature, } \\
{ }^{\circ} \mathbf{C}\end{array}$ & $\begin{array}{c}\text { Sorption } \\
\text { time, } \\
\text { min }\end{array}$ & $\begin{array}{c}\text { Sorptive } \\
\text { capacity, } \\
\text { g SO } / \mathbf{g} \\
\text { moisture-free } \\
\text { sorbent (0.5-1 } \\
\text { mm pellets) }\end{array}$ \\
\hline 1. & $\begin{array}{c}\text { FMN-wet } \\
\text { Humidity } \\
43 \%\end{array}$ & 1.5 & 25 & 111 & 0.22 \\
\hline 2. & $\begin{array}{c}\text { FMN- } \\
100^{\circ}+\mathrm{H}_{2} \mathrm{O} \\
\text { Humidity } \\
43 \%\end{array}$ & 1.5 & 25 & 107 & 0.21 \\
\hline 3. & $\begin{array}{c}\text { FMN- air } \\
\text { dried } \\
\text { Humidity } \\
18 \%\end{array}$ & 1.1 & 25 & 32 & 0.06 \\
\hline 4. & $\begin{array}{c}\text { FMN-100 } \\
\text { Humidity } \\
14 \%\end{array}$ & 1.1 & 25 & 26 & 0.05 \\
\hline
\end{tabular}

Sorptive capacity of FMN samples for $\mathrm{SO}_{2}$ was found to increase with humidity of the sorbents. In the case of a dry $\mathrm{SO}_{2}$-containing gas mixture fed on dry adsorbents at $25^{\circ} \mathrm{C}$, total capacity of the samples was 0.05-0.06 $\mathrm{g} \mathrm{SO}_{2} / \mathrm{g}$ moisturefree adsorbent. Sorptive capacity, which was measured before a breakthrough of $\mathrm{SO}_{2}$, of the samples of wet FMN or dry FMN moistened to a humidity of $43 \%$ was $0.21-0.22 \mathrm{~g} \mathrm{SO}_{2} / \mathrm{g}$ moisture-free sorbent. This suggests that at the beginning of the process $\mathrm{SO}_{2}$ is oxidized by air oxygen to $\mathrm{SO}_{3}$, which readily dissolves in water with the formation of sulfuric acid. After that, $\mathrm{H}_{2} \mathrm{SO}_{4}$ is adsorbed by $\mathrm{Mn}$ and $\mathrm{Fe}$ oxides to yield respective sulfates until deactivation of the samples. As the sorption temperature increases to 90 and $150^{\circ} \mathrm{C}$, which decreases humidity of the samples, the sorptive capacity for $\mathrm{SO}_{2}$ decreases (Table 4 and Fig. 3). A further raising of the process temperature to $350^{\circ} \mathrm{C}$ increases sorptive capacity of the samples, which may be related to a 1.5 -fold extension of the pore volume.

TABLE 4. Sorptive Capacity of FMN Samples for $\mathrm{SO}_{2}$ Versus Sorption Temperature

\begin{tabular}{|c|c|c|c|c|c|}
\hline No. & Sample & $\begin{array}{l}\text { Sample } \\
\text { weight, } \\
\quad \mathrm{g}\end{array}$ & $\begin{array}{l}\text { Adsorption } \\
\text { temperature, } \\
{ }^{\circ} \mathrm{C}\end{array}$ & $\begin{array}{l}\text { Sorption } \\
\text { time, } \\
\text { min }\end{array}$ & $\begin{array}{c}\text { Sorptive } \\
\text { capacity, } \\
\text { g SO } / \text { /g } \\
\text { moisture-free } \\
\text { sorbent }(0.5-1 \\
\text { mm pellets) }\end{array}$ \\
\hline \multirow{5}{*}{1.} & \multirow{5}{*}{$\begin{array}{c}\mathrm{FMN}-100^{\circ} \\
\text { Humidity = } \\
14 \%\end{array}$} & \multirow{5}{*}{1.1} & 25 & 25 & 0.05 \\
\hline & & & 50 & 34 & 0.06 \\
\hline & & & 90 & 12 & 0.02 \\
\hline & & & 150 & 10 & 0.02 \\
\hline & & & 350 & 46 & 0.08 \\
\hline \multirow{3}{*}{2.} & \multirow{3}{*}{$\begin{array}{c}\text { FMN - wet } \\
\text { Humidity = } \\
43 \%\end{array}$} & \multirow{3}{*}{1.5} & 25 & 111 & 0.22 \\
\hline & & & 90 & 47 & 0.09 \\
\hline & & & 350 & 53 & 0.1 \\
\hline \multirow{5}{*}{3.} & \multirow{5}{*}{$\begin{array}{c}\mathrm{FMN}- \\
100^{\circ}+\mathrm{H}_{2} \mathrm{O} \\
\text { Humidity = } \\
43 \%\end{array}$} & \multirow{5}{*}{1.5} & 25 & 107 & 0.21 \\
\hline & & & 50 & 76 & 0.15 \\
\hline & & & 90 & 33 & 0.065 \\
\hline & & & 150 & 27 & 0.05 \\
\hline & & & 350 & 44 & 0.09 \\
\hline
\end{tabular}

\section{CONCLUSION}

Physicochemical properties of FMN samples (as pellets and powder) were studied in dependence on the calcination temperature. The FMN samples calcined over the temperature range of $100-400^{\circ} \mathrm{C}$ were shown to have quite high specific surface areas, $150-158 \mathrm{~m}^{2} / \mathrm{g}$, which are determined by the number of fine pores. When the calcination temperature exceeds $550^{\circ} \mathrm{C}$, the mesopore volume sharply decreases and large pores gradually sinter, which is accompanied by deterioration of all parameters of the pore structure, both the specific surface area and the total pore volume. According to XRD data, the starting FMN sample is characterized by an Xray amorphous phase. Well crystallized phases of iron oxides corresponding to hematite and magnetite are observed for the samples calcined at $700^{\circ} \mathrm{C}$ and higher temperatures.

FMN samples were tested in the sorption of $\mathrm{SO}_{2}$. It was found that the sorptive capacity of FMN samples for $\mathrm{SO}_{2}$ increases with humidity of adsorbents. The FMN samples with a humidity above $40 \%$ were shown to be promising for the removal of sulfur dioxide from gases. Sorptive capacity of wet FMN can be as high as $0.22 \mathrm{~g} \mathrm{SO}_{2} / \mathrm{g}$ moisture-free sorbent, which is an appropriate value for industrial application of ferromanganese nodules in the removal of $\mathrm{SO}_{2}$ from flue gases.

\section{ACKNOWLEDGMENT}

The study was performed with financial support of the state in the name of the Ministry of Education and Science of 
the Russian Federation within implementation of the Federal target program 'Researches and Development on the Priority Directions of Development of the Scientific and Technological Complex of Russia for 2014-2020', as per the Agreement №14.583.21.0004 on the subsidy granting of July 16, 2014. The unique identifier of scientific researches (project) is RFMEFI58314X0004.

\section{REFERENCES}

[1] Boreskov G.K., Levitsky E.A., Ismagilov Z.R. // Journal of the AllUnion Mendeleev Chemical Society, Vol. XXIX, No. 4, p. 379-385, 1984

[2] Ismagilov Z.R., Kerzhentsev M.A. // Journal of the All-Union Mendeleev Chemical Society, Vol. XXXV, No. 1, p. 43-53, 1990

[3] Ismagilov Z.R., Kerzhentsev M.A. // Catal. Rev. Sci.\& Eng. 1990, Vol 32, Nos $1 \& 2$, p. 51-103

[4] Ismagilov Z.R., Schipko M.L., Bogomolov S.V., Kerzhentsev M.A. // Chemistry For Sustainable Development, 1996, Vol. 4, No. 6, p. 473 480

[5] Tarelho L.A.C., Matos M.A.A., Pereira F.J.M.A. // Fuel Process. Technol. 2005. Vol. 86. No. 12-13. P. 1385

[6] Ridha F.N., Manovic V., Macchi A., Anthony E.J. // Appl. Energy. 2012. Vol. 92. P. 415

[7] Yan L., Lu X., Wang Q., Kang Y., Xu J., Chen Ye. // Appl. Therm. Eng. 2014. Vol. 65. P. 487

[8] Ansari A., Bagreev A., Bandosz T.J. // Carbon. 2005. Vol. 43. No. 2. P. 359
[9] Bandosz T. J., Block K.// Ind. Chem. Eng. Res. 2006. Vol. 45. No. 10. P. 3666

[10] Bagreev A., Bandosz T. J. // J. Colloid Interface Sci. 2002. Vol. 252. P. 188

[11] Bagreev A., Bashkova S., Locke D.C., Bandosz T.J. Sewage Sludge Derived Materials as Adsorbents for $\mathrm{H}_{2} \mathrm{~S}$ and $\mathrm{SO}_{2}$. // Fundamentals of Adsorption -7, K. Kaneko, H. Kanoh, Y. Hanzawa Eds., IK International, Chiba, Japan. 2002. P. 239

[12] Bashkova S., Bagreev A., Locke D.C., Bandosz T.J. // Environ. Sci. Technol. 2001. Vol. 35. P. 3263

[13] Malikov F.L., Mukhlenov I.P., Mirzarakhimov M.S. // Journal of Applied Chemistry, 1981. Vol. 64. P. 2296

[14] RF patent 2164445, 2001

[15] Jang H.T., Kim S.B., Doh D.S. // Korean J. Chem. Eng. 2003. Vol. 20. No. 1. P. 116

[16] Yoon Y. I., Kim M.W., Yoon Y. S., Kim S.H. // Chem. Eng. Sci. 2003. Vol. 58. No.10. P. 2079

[17] Jeong S.K., Park T.S., Hong S.C. // J. Chem. Techn.\& Biotechn. 2001 Vol. 76. No. 10. P. 1080

[18] Nitta M. // Appl. Catal. 1984. Vol. 9. P. 151

[19] US Patent 3330096, 1967

[20] Romanchuk A.I., Ivanovskaya V.P., Matevich T.N., Korolev A.B. // Ores and Metals. 1995. No. 4. P. 100

[21] Ivanova A.M., Smirnov A.N., Rogov V.S., Motov A.P., Nikolskaya N.S., Palshin K.V. // Mineral Resources of Russia. 2006. No. 6. P. 14

[22] Z.R. Ismagilov, Khairulin S.R., Yashnik S.A., Ilyukhin I.V., Parmon V.N. // Catalysis in Industry, 2008, special issue. P. 73-79 